\title{
INFLUENCE OF ELECTROLYTES IN THE ELECTRICAL CHARACTERISTICS OF ANODIC FILMS ON TANTALUM
}

\author{
M. FERNÁNDEZ, J. BAONZA, J. M. ALBELLA and J. M. MARTÍNEZ-DUART \\ Instituto de Física del Estado Sólido, CSIC and Departamento de Física Aplicada. Universidad Autónoma, \\ Cantoblanco, Madrid, 34. Spain
}

(Received August 1, 1979; in final form April 23, 1980)

\begin{abstract}
The electrical characteristics of anodic oxide films formed on tantalum are investigated in anodes oxidized in the standard electrolytes for low-voltage $\left(0.01 \% \mathrm{H}_{3} \mathrm{PO}_{4}\right.$ in water) and high-voltage (same plus ethylene glycol) applications. It is found that small additions (about $0.1 \%$ ) of certain organic acids such as citric acid to the above electrolytes greatly improves the leakage current, the scintillation voltage and the dielectric losses of tantalum capacitors. Furthermore, the use of these organic acids makes it possible to extend to higher voltages the use of the low-voltage electrolyte, and allows, in the case of the high-voltage electrolyte, a substantral diminution in the ethylene glycol concentration without impairing the characteristics of the resulting capacitors. Finally, the effect of the citric acid and the ethylene glycol in the anodizing electrolytes is discussed.
\end{abstract}

\section{INTRODUCTION}

The growth and properties of $\mathrm{Ta}_{2} \mathrm{O}_{5}$ thin films formed by the anodic oxidation of tantalum have been extensively studied. ${ }^{1}$ Phosphoric acid, $\mathrm{H}_{3} \mathrm{PO}_{4}$, is probably the most widely used electrolyte in the formation of anodic dielectric films for use in tantalum electrolytic capacitors. ${ }^{2}$ The phosphorus ions which are incorporated in the $\mathrm{Ta}_{2} \mathrm{O}_{5}$ film during the oxidation in $\mathrm{H}_{3} \mathrm{PO}_{4}$ strongly influence several of the oxide's properties such as chemical stability and dielectric constant. ${ }^{3}$ It is usual practice in the tantalum capacitor industry, for voltages lower than $200 \mathrm{~V}$, to form the oxide in a diluted aqueous solution of $\mathrm{H}_{3} \mathrm{PO}_{4}$ (from 0.01 to $0.1 \%$ ). However, for higher voltages, other solvents such as ethylene glycol are added in high concentrations (about 50\%) in order to increase the electrolyte's scintillation voltage. ${ }^{4}$ This is also the case in the anodic oxidation of other metals (e.g. $\mathrm{Al}, \mathrm{Bi}, \mathrm{Mo}, \mathrm{Ti})^{5}$ and semiconductors (e.g. Si, AsGa). ${ }^{6}$

In addition to the above electrolytes, other electrolytes based on organic acids seem to form very good quality $\mathrm{Ta}_{2} \mathrm{O}_{5}$ films. Among the organic acids, citric acid is extensively used in the anodization of sputtered tantalum films ${ }^{7}$ and has also been proposed as an additive for the working electrolyte in aluminum electrolytic capacitors.

In spite of the extensive use of the electrolytes which we have mentioned, there does not exist a thorough study of some of the basic properties of the oxide (scintillation voltage, leakage current, dielectric losses) which influence the resulting capacitor. In particular, it might be interesting to find mixtures of electrolytes which would optimize the quality of the resulting oxide, as well as reduce the amount of the expensive ethylene glycol used in the high voltage electrolyte.

\section{EXPERIMENTAL}

Two types of sintered tantalum anodes, provided by two different suppliers, were used in this work: (i) Ta anodes with a capacity-voltage product $\mathrm{CV}$ of $164 \mu \mathrm{F} \cdot \mathrm{V}$ and a weight of $0.04 \mathrm{~g}$; and (ii) Ta anodes with $\mathrm{CV}=188 \mu \mathrm{F} \cdot \mathrm{V}$ and weighing $0.09 \mathrm{~g}$. The difference in the relation between $\mathrm{CV}$ product and weight is due to the different pressed density of the anode (green density) as well as to the size of the powder.

Tantalum anodes for solid electrolytic capacitors are generally oxidized in an aqueous solution $(0.01 \%)$ of $\mathrm{H}_{3} \mathrm{PO}_{4}$ (L.V. electrolyte) up to formation voltages, $\mathrm{V}_{\mathrm{f}}$, of $180 \mathrm{~V}$ to $200 \mathrm{~V}$, and in a mixture of $45 \%$ of the former electrolyte and 55\% of ethylene glycol (standard H.V. electrolyte) for high voltage uses $\left(\mathrm{V}_{\mathrm{f}}\right.$ higher than $180 \mathrm{~V}$ to $\left.200 \mathrm{~V}\right)$. In this work the tantalum anodes were anodized at $85^{\circ} \mathrm{C}$ in the above standard electrolytes, to which varying amounts of 
citric acid were added. The anodization was performed at a constant current of $0.04 \mathrm{~A} / \mathrm{g}$. The measurement of the leakage current was accomplished by placing the anodes in a $10 \% \mathrm{H}_{3} \mathrm{PO}_{4}$ aqueous solution and polarizing the anodes with a voltage one fourth of the formation voltage during a time of $10 \mathrm{~min}$.

During the anodization at a constant current density, the voltage increases linearly with time, until a voltage is reached at which oscillations start to appear in the anodization curve. This voltage is usually known as the scintillation voltage, since the oscillations in the $V=V(t)$ curve correspond to breakdown events which are accompanied by sparks at the oxide's surface. In the electrolytes based on $\mathrm{H}_{3} \mathrm{PO}_{4}$ and water, the first scintillation sparks produce an abrupt decay in the voltage which allows $\mathrm{V}_{b}$ to be identified unequivocally. In other cases the initiation of the scintillation phenomena is better appreciated by electronically differentiating the $V=V(t)$ curve and amplifying the function $d V(t) / d t$ subsequently. A detailed description of the pulse detector and counter of the peaks in the derivative curve is given elsewhere. ${ }^{8}$

\section{RESULTS}

Results on the dielectric characteristics of different tantalum anodes were obtained for various concentrations of the standard L.V. and H.V. electrolytes. The capacitance and dielectric losses were measured at $0.1 \mathrm{kHz}$ and $1 \mathrm{kHz}$ with a Hewlett-Packard 4261 A automatic LCR bridge. At these low frequencies, the capacitance was found to be practically independent of the composition of the electrolyte employed. However, the leakage current, the scintillation voltage and the dielectric losses, which are more sensitive to the quality of the oxide, changed appreciably with the electrolyte composition.

\subsection{Leakage Current}

Figure 1(a) shows the leakage current $I_{l}$ for the $\mathrm{CV}=188 \mu \mathrm{F} \cdot \mathrm{V}$ anodes formed in the L.V. electrolyte to which various amounts of citric acid were added. The curve represents the average $\mathrm{I}_{l}$ for several samples, usually five. The typical deviation between measurements before taking the average is about $50 \%$ and the maximum deviations were always

\section{$\%$ Glycol added to $\mathrm{H}_{3} \mathrm{PO}_{4}+0,15 \%$ citric}

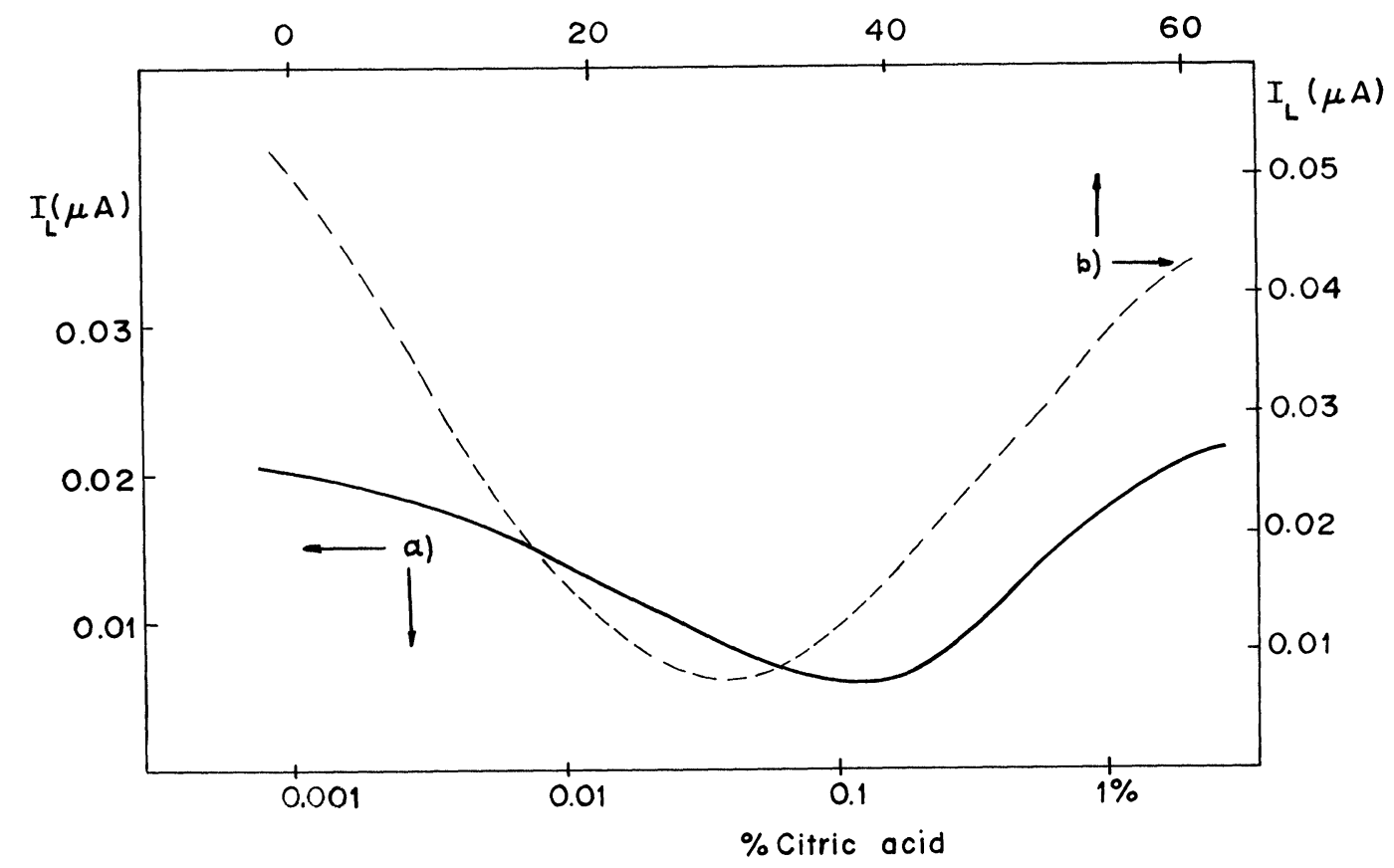

FIGURE 1 Leakage current vs.\% citric acid. (a) Leakage current for tantalum anodes formed in the L.V. electrolyte $\left(\mathrm{V}_{f}=170 \mathrm{~V}\right)$ with various amounts of citric acid. (b) Leakage current for anodes formed to $300 \mathrm{~V}$ in a H.V. electrolyte of the following composition: $0.15 \%$ citric acid, varying concentrations of ethylene gly col in water, and enough $\mathrm{H}_{3} \mathrm{PO}_{4}$ to give $\rho=440 \Omega \mathrm{cm}$. 
kept within an order of magnitude (the variations in $\mathrm{I}_{l}$ for different samples can be in part attributed to the uncertainty in the area of the anodes). For anodization voltages ranging from $100 \mathrm{~V}$ to $200 \mathrm{~V}$, curves similar to the one shown in Figure 1(a) were obtained. For voltages higher than $200 \mathrm{~V}$, the H.V. electrolyte was always employed since the L.V. electrolyte, without ethylene glycol, started to show instabilities, i.e., the anodes had large, and often unpredictable, values of $\mathrm{I}_{l}$. From Figure 1(a) and similar curves for $100 \mathrm{~V}<\mathrm{V}_{f}<200 \mathrm{~V}$, it can be appreciated that the leakage current for the anodes studied shows a value of about $0.02 \mu \mathrm{A}$, but for a concentration of citric acid of $0.1 \%$ to $0.2 \%$ added to the L.V. electrolyte, $\mathrm{I}_{l}$ decreases to about one fourth of this value. Concentrations of citric acid higher than $1 \%$ do not show this remarkable healing effect. Comparable results were obtained for the anodes with a CV product of $164 \mu \mathrm{F} \cdot \mathrm{V}$.

The addition of citric acid in appropriate concentrations, besides reducing the leakage current for anodes oxidized in the L.V. electrolyte, shows a similar effect when it is added to the H.V. electrolyte. This effect is more important at low ethylene glycol concentrations, as shown in Table I for tantalum anodes with $\mathrm{CV}=164 \mu \mathrm{F} \cdot \mathrm{V}$ anodized at $300 \mathrm{~V}$. As in the case of the L.V. electrolyte, a concentration of $0.15 \%$ citric acid added to the H.V. electrolyte was also the most appropriate in order to get a minimum in the value of the leakage current.

For an electrolyte formed with a given concentration of ethylene glycol in water (varying from 0 to $55 \%$ ), $0.15 \%$ citric acid, and enough $\mathrm{H}_{3} \mathrm{PO}_{4}$ to give a resistivity of $\rho=440 \Omega \mathrm{cm}$, the leakage current was next investigated as a function of ethylene glycol concentration. This was done with the object of finding electrolytes with much less ethylene glycol concentration than the H.V. electrolyte but having essentially the same or improved formation characteristics. Figure 1(b)

\section{TABLE I}

Leakage current in $\mu \mathrm{A}$ for $\mathrm{Ta}$ anodes formed in electrolyte $\mathrm{A}$ (ethylene glycol and $\mathrm{H}_{3} \mathrm{PO}_{4}$ ) and electrolyte $\mathrm{B}$ (same plus $0.15 \%$ citric acid) for various ethylene glycol concentrations. The resistivity of both electrolytes is $\rho=440 \Omega \mathrm{cm}$.

\begin{tabular}{lll}
\hline $\begin{array}{l}\text { Ethylene- } \\
\text { glycol conc. }\end{array}$ & Electrolyte A & Electrolyte B \\
\hline $10 \%$ & 0.400 & 0.040 \\
$15 \%$ & 0.025 & 0.014 \\
$25 \%$ & 0.012 & 0.008 \\
$55 \%$ & 0.010 & - \\
\hline
\end{tabular}

shows in this case the dependence of $\mathrm{I}_{l}$ as a function of the ethylene glycol concentration. It can be observed that for the modified H.V. electrolyte with $0.15 \%$ citric acid, the most suitable concentration of ethylene glycol is about $25 \%$, and that fairly good characteristics are still obtained with only $15 \%$.

It might also be significant to study the behaviour of the leakage current as a function of the voltage of polarization and therefore better show the effect of adding citric acid, in appropriate concentrations, to the high voltage electrolyte. Figure 2 shows such characteristic curves for Ta anodes oxidized in the high voltage electrolyte at various ethylene glycol concentrations. It can be again observed that for a given ethylene glycol concentration the use of the electrolytes with citric acid results in a substantially smaller leakage current. In addition, since the characteristic curves of $\log \mathrm{I}_{l}$, vs V show a smaller slope for the electrolytes with citric acid, their relative behaviour improves as the polarizing voltage increases.

\subsection{Scintillation Voltage}

Figure 3 shows the influence of the citric acid, added to the L.V. electrolyte $(\rho=120 \Omega \mathrm{cm})$, on the scintillation voltage. It can be observed that the addition of small amounts of citric acid produces an increase in $\mathrm{V}_{b}$. The relation between $\mathrm{V}_{b}$ and the $\log$ of the electrolyte's resistivity is linear, but with negative slope. This last fact contradicts the result found with a large number of electrolytes, which show a small positive slope. ${ }^{9}$

The addition of citric acid to the H.V. electrolyte was examined for the anodes with $\mathrm{CV}=188 \mu \mathrm{F} \cdot \mathrm{V}$ (Table II). When citric acid is added to the H.V. electrolyte there appear two beneficial effects: a) The scintillation voltage can be increased by about $100 \mathrm{~V}$, and b) The increase is most effective for ethylene glycol concentrations of the order of $25 \%$, thus allowing a reduction in the recommended amount of $55 \%$ when no use of citric acid is made.

\subsection{Dielectric Losses}

The addition of citric acid to the L.V. electrolyte has little effect on $\tan \delta$, but it is more significant in the H.V. electrolyte as it can be observed in Table III for two different voltages. This table also shows the effect of the citric acid in the high voltage electrolytes with different ethylene glycol concentrations. For an ethylene glycol concentration around $25 \%$ the value of $\tan \delta$ shows a minimum. 


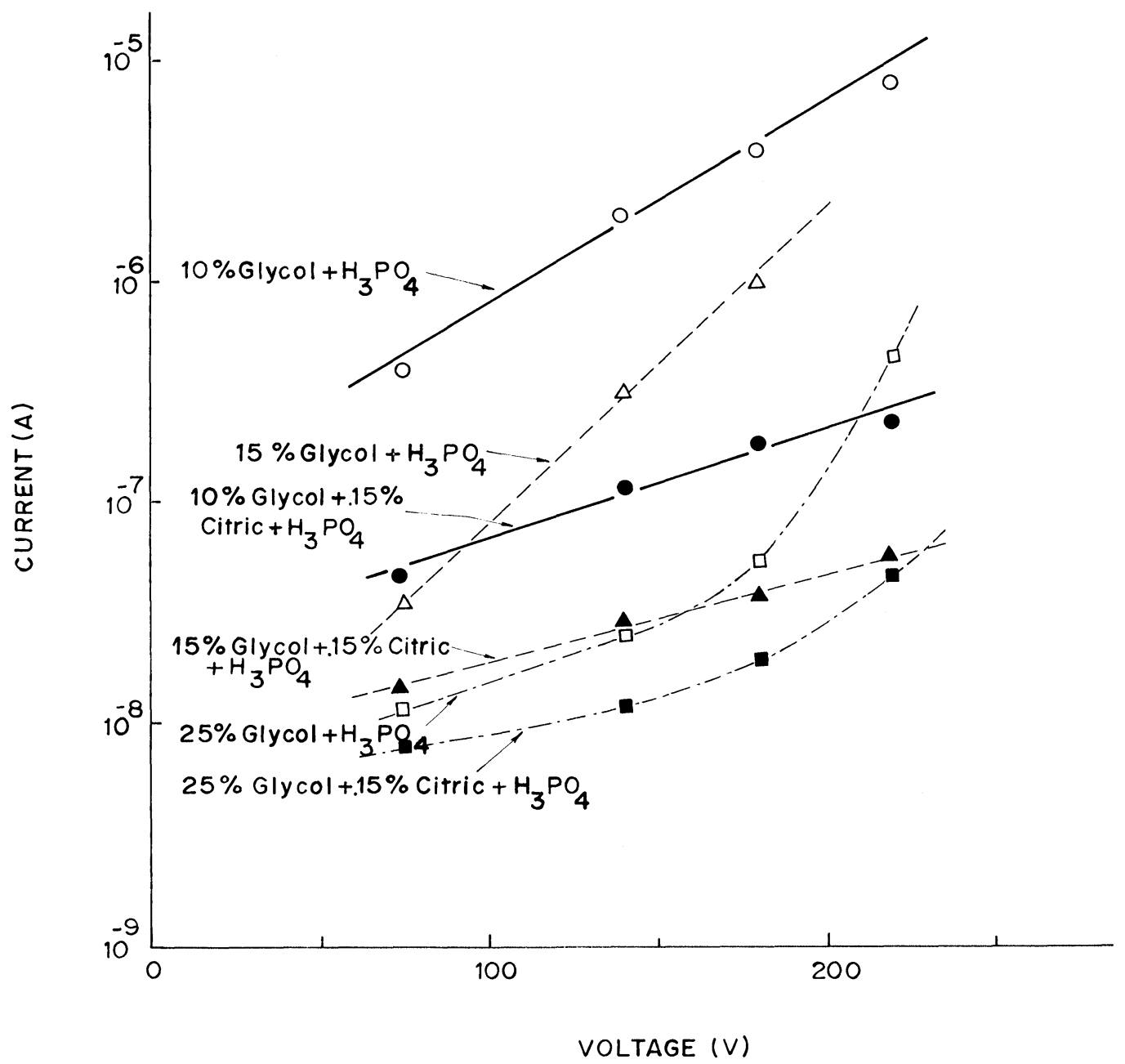

FIGURE 2 Leakage current as a function of the voltage of polarization for several H.V. electrolytes $\left(\mathrm{V}_{f}=300 \mathrm{~V}\right.$ and $\mathrm{CV}=164 \mu \mathrm{F} \cdot \mathrm{V})$.

\section{DISCUSSION AND CONCLUSIONS}

From the above experimental facts it seems to be well established that the addition of small amounts of citric acid (about $0.1 \%$ to $0.2 \%$ ) in the standard L.V. and H.V. electrolytes for tantalum anodes produces several beneficial effects: (i) It reduces to about one fourth the leakage current of anodes formed in the L.V. electrolytes (Figure 1a); (ii) For H.V. electrolytes, the leakage current might be reduced by up to one order of magnitude when low ethylene glycol concentrations are used (Table I);

(iii) It increases by about $60 \mathrm{~V}$ the scintillation voltage of the L.V. electrolyte (Figure 3); (iv) If the citric acid is added to the high voltage electrolytes with varying amounts of ethylene glycol (up to 55\%), it gives, for a concentration of around $25 \%$, a minimum in both the leakage current and in the dielectric losses and a maximum in the scintillation voltage (Figure $1 \mathrm{~b}$ and Tables II and III).

As checked by the authors, the addition of $0.1 \%$ to $0.2 \%$ of citric acid to the L.V. electrolyte allows its use to be extended by about $50 \mathrm{~V}$. Therefore, this electrolyte without ethylene glycol can, in principle, be substituted for the more expensive H.V. electrolytes up to formations of around $240 \mathrm{~V}$ to $250 \mathrm{~V}$, producing anodes of essentially the same characteristics. In the case of oxidations above $250 \mathrm{~V}$, 


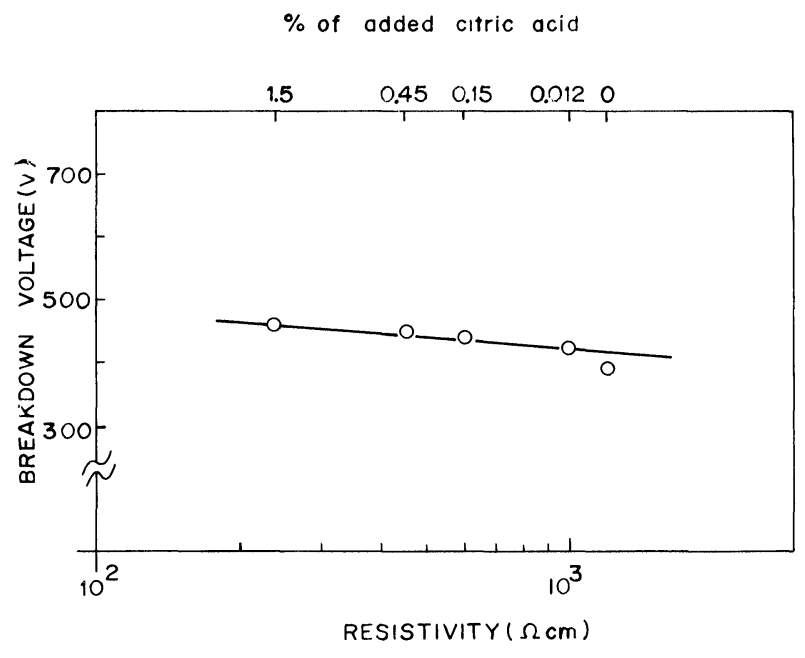

FIGURE 3 Influence of the citric acid added to the L.V. electrolyte on the scintillation voltage for anodes with $\mathrm{CV}=188 \mu \mathrm{F} \cdot \mathrm{V}$.

the use of ethylene glycol proved to be necessary in the fabrication of high quality capacitors. However, by adding citric acid, the concentration of ethylene glycol could be diminished by a factor between 2 and 3 , resulting in significant savings and producing anodes with improved properties.

Although citric acid in aqueous solutions has

TABLE II

Scintillation voltage for the H.V. electrolyte with the addition of citric acid $(\rho=440 \Omega \mathrm{cm})$

\begin{tabular}{ll}
\hline Glycol $(15 \%)+$ citric $(0.15 \%)+$ phosphoric & $508 \mathrm{~V}$ \\
Glycol $(25 \%)+$ citric $(0.15 \%)+$ phosphoric & $535 \mathrm{~V}$ \\
Glycol $(55 \%)+$ citric $(0.15 \%)+$ phosphoric & $434 \mathrm{~V}$ \\
Glycol $(55 \%)+$ phosphoric & $434 \mathrm{~V}$ \\
\hline
\end{tabular}

been known for its good anodizing characteristics for sputtered tantalum, ${ }^{7}$ it is difficult to know the reason for its influence in the final properties of the tantalum anodes studied in this work. Burger and $\mathrm{Wu}^{10}$ ascribe the beneficial effect of the citric acid to its capability to form chelating complexes with the metal surface impurities, thus healing the weak areas of the surface which serve as a path for the leakage current. The chelating properties might be attributed to the combined effects of the radicals of certain organic acids such as citric:<smiles>CC(O)C(C)C(=O)O</smiles>

In this sense, it might be interesting to remark that from the point of view of leakage currents, the authors have verified that other organic acids, e.g. tartaric, with the same kind of radicals as citric, give similar results. However, organic acids, such as propionic, lacking in part the structure (1), give worse results.

Due to the effect of the ethylene glycol, the H.V. electrolyte, when used at high voltages, show better anodizing characteristics than the L.V. electrolyte, i.e. the resulting anodes have smaller $\mathrm{I}_{l}$ and higher $\mathrm{V}_{b}$. This might be due to the fact that the ethylene glycol traps free water molecules from the electrolyte, resulting in better characteristics and efficiency of the anodization process. ${ }^{11}$ Moreover, it has been shown by Jackson that the use of ethylene glycol as a solvent for anodizing electrolytes produces a strong inhibition of the oxide's electric-field induced crystallization. ${ }^{12}$ This fact can explain the observed decrease in the leakage current for electrolyte A (Table I) and the generally accepted fact that the scintillation voltage is higher for electrolytes with ethylene glycol. ${ }^{4}$

TABLE III

$\tan \delta$ at $0.1 \mathrm{kHz}$ and $1 \mathrm{kHz}$ for $\mathrm{CV}=188 \mu \mathrm{F} \cdot \mathrm{V}$ anodes formed at two different voltages in the H.V. electrolyte with $0.15 \%$ citric acid $(\rho=440 \Omega \mathrm{cm})$.

\begin{tabular}{clll}
\hline & & $0.1 \mathrm{kHz}$ & $1 \mathrm{kHz}$ \\
\hline $\mathrm{V}_{f}=200 \mathrm{~V}$ & $55 \%$ glycol + phosphoric & 0.015 & 0.117 \\
& $55 \%$ glycol + phosphoric + citric & 0.011 & 0.087 \\
\hline $\mathrm{V}_{f}=300 \mathrm{~V}$ & $8 \%$ glycol + phosphoric + citric & 0.0083 & 0.054 \\
, & $15 \%$ glycol + phosphoric + citric & 0.0086 & 0.057 \\
, & $25 \%$ glycol + phosphoric + citric & 0.0073 & 0.051 \\
, & $55 \%$ glycol + phosphoric + citric & 0.0098 & 0.070 \\
\hline
\end{tabular}




\section{ACKNOWLEDGEMENTS}

We would like to acknowledge the American-Spanish Committee for Scientific and Technological Cooperation and PIHER S.A. (Barcelona, Spain) for partial support of this work.

\section{REFERENCES}

1. W. D. Westwood, N. Waterhouse and P. S. Wilcox, Tantalum Thin Films. Academic Press, London (1975)

2. W. J. Bernard, "Developments in electrolytic capacitors" J. Electrochem. Soc. 124, 403c (1977).

3. D. M. Smyth, T. B. Tripp and G. A. Shirn, "Heat treatment of anodic oxide films on Tantalum. IV Anodization in Phosphoric acid solutions." J. Electrochem. Soc. 113, 100 (1966).

4. K. Knoblauch and E. Oldekop, Verfahren zur formierung von tantal-oder Niobkorpen, insbesondere fur elektroden in elektrolytkondensatoren. German Patent, 1.978. 275 (1964).
5. L. Young, Anodic Oxide Films Academic Press, London (1961).

6. H. Hasegawa and H. L. Hartnagel, "Anodic oxidation of GaAs in mixed solutions of Glycol and Water" J. Electrochem. Soc. 123, 713 (1976).

7. D. Gerstemberg Handbook of Thin Film Technology, chapter 19, Ed. L. I. Maissel and R. Glang, McGraw-Hill N.Y. (1970).

8. J. M. Albella, I. Montero, J. Baonza and J. M. Martinez-Duart, "Pulse counting in anodic breakdown measurements" Electrocomp. Sci. Techn. 7, 201 (1981).

9. F. J. Burger and J. C. Wu, "Dielectric breakdown in electrolytic capacitors" J. Electrochem. Soc. 118, 2039 (1971)

10. F. J. Burger and J. C. Wu, Aluminum electrolytic capacitor U.S. Patent, 3.676 .752 (1972).

11. B. R. Evans, The Corrosion and Oxidation of Metals, Edward Arnold Ltd., London (1960).

12. N. F. Jackson, "Field crystallization of anodic films on tantalum" J. Appl. Electrochem. 3, 91 (1973). 

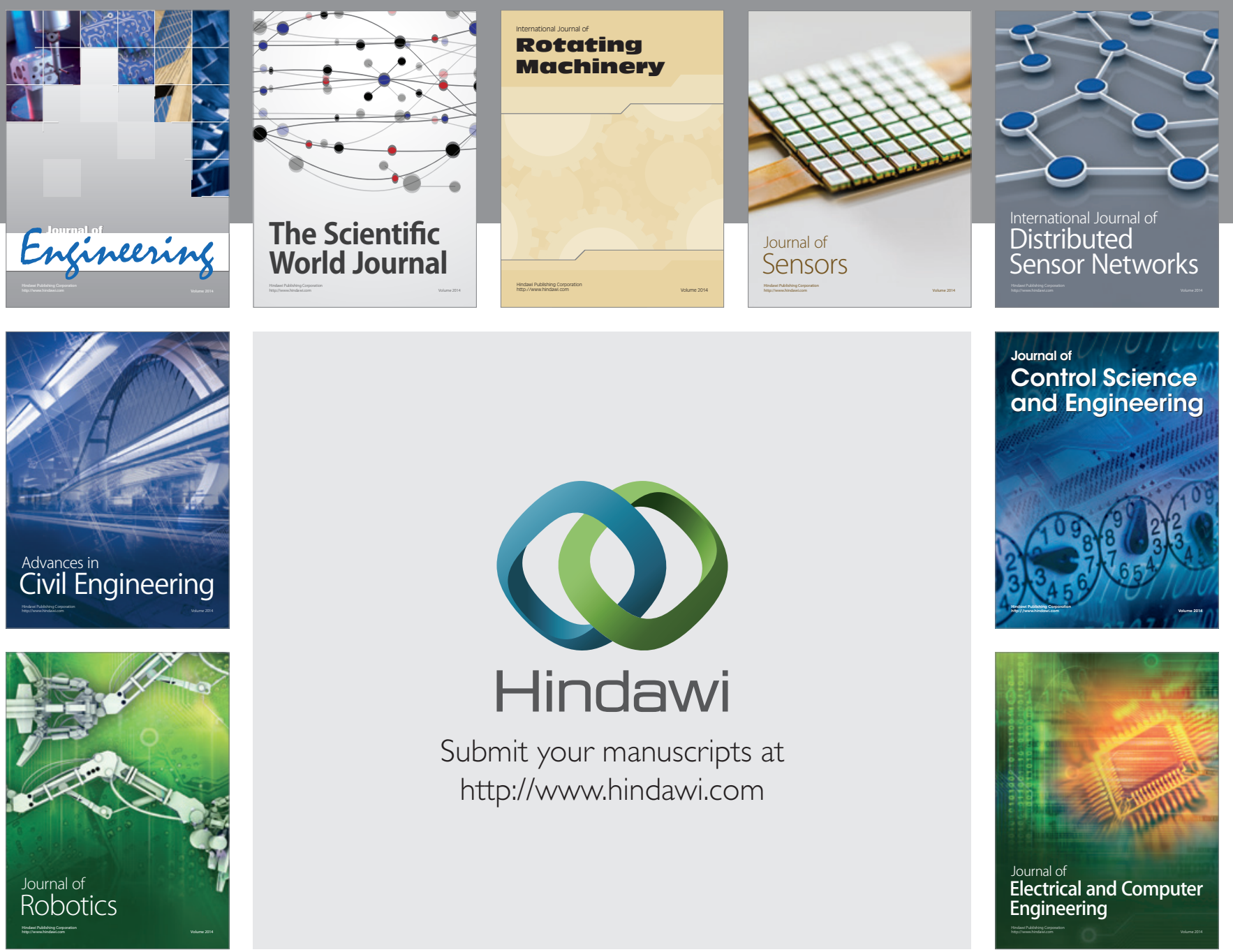

Submit your manuscripts at

http://www.hindawi.com
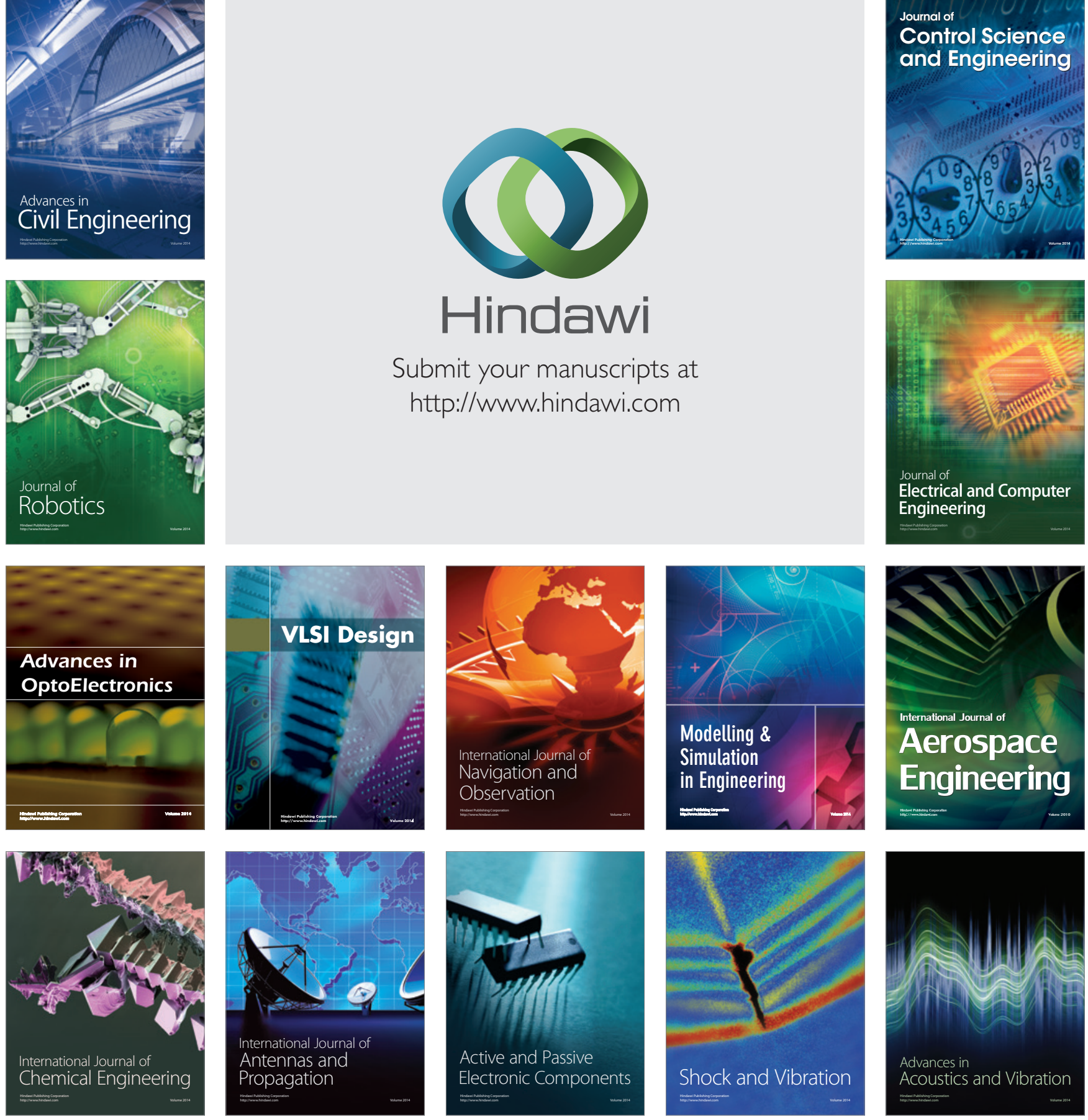